Journal of Social Sciences 1 (3): 166-171, 2005

ISSN 1549-3652

(c) 2005 Science Publications

\title{
Origin and Trend of Distance Education in Uganda
}

\author{
${ }^{1}$ Bbuye Juliana and ${ }^{2}$ Mango Magero John \\ ${ }^{1}$ Department of Distance Education, ${ }^{2}$ Department of Mathematics \\ Makerere University ,7062 Kampala, Uganda
}

\begin{abstract}
Distance education has been in existence in Uganda since the 1960s, and it has grown steadily since that time. It is however a neglected area in terms of data collection and research. The courses that were running between 1960 and 1980s have scanty documentation. What can be traced include the upgrading course for teachers which upgraded 1000 teachers from vernacular teachers to grade 1 and grade II teachers. This was repeated with 789 more teachers. There is hardly any documentation on correspondence courses Ugandans took with the various British based correspondence institutions like Rapid College Correspondence School. In the following section this study takes you through the historical development of distance education in Uganda and through the various donor funded programs of which, some have ended already, but which do offer great lessons to learn from. It also takes you through distance education at higher levels of learning, as well as distance education in non-formal education. In conclusion the study discusses some of the challenges Uganda faces in its attempt to offer modern distance education, the rather scanty achievements so far reached in that area, and proposes a way forward in form of some indicative recommendations.
\end{abstract}

Key words: Distance education, modern distance education, correspondence school

\section{INTRODUCTION}

The historical development: Distance education is not a new phenomenon in Uganda. In the 1960s Uganda realized the growth of a number of Corresponding courses, not with standing the many Ugandans who enrolled in the British correspondence colleges and obtained qualifications of general certificate of education (GCE) or Cambridge school certificate or advanced certificates and accountancy qualifications. Since then it has grown tremendously though with disturbances during the disturbed years of civil wars Indeed a number of scholars such as Aguti ${ }^{[1]}$, Nsamba and Atim $^{[2]}$ and Bbuye $^{[3]}$ observe that Uganda has witnessed a steady growth in the development and refining of the provision of distance education in the country. The Kironde Report ${ }^{[4]}$ focusing on the need to provide continuing education to various expectant groups in Uganda, recommended that correspondence education be expanded and that Makerere University begin to offer courses in that field leading later to the establishment of an Open University in Uganda. Prior to the 1960s however, we note the rather disguised running of distance education programs on the national radio. Muwanga ${ }^{[5]}$ observes that as early as 1954 , radio was playing a major role in teaching the masses how to solve important social and economic problems in the development of the colonial territory of Uganda. In addition to general programs, school radio educational programs began to run in Uganda. The school education programs unfortunately did not actually mature because of a various reasons. Muwanga ${ }^{[5]}$ again cites the total lack of personal contact between producers and consumers, which was being reflected in the haphazard use of educational radio and television. The programs were broadcast when most schools had other items on the curriculum. However the schools that could liaise well with the educational radio and television unit in the ministry gained and still gain from such programs Makerere University was the pioneer of running correspondence courses within the country. Among the many courses run were; good letter writing, upgrading of grade 111 teachers to grade IV, the intermediate course, and the clerical entrance course. What is unusual in the development process of distance education is a continuous decline in the provision of distance education. The late 1970s and 1980s were years of upheaval in Uganda and little were done as far as distance education is concerned. It is only in the early 1990s that we begin to see a ray of hope through donor funding of project distance education programs, though most of them have ended. Renewed activity in distance education in Uganda therefore began only in the late 1980s and the 1990s when the Mubende Integrated Teacher Education project (MITEP) began and was replicated in the other distance education programs that sprang up in the country such as the Northern Uganda Integrated Teacher Education Project (NITEP) Rakai Integrated Teacher Education Project (RITEP) and Teacher Development Management Services (TDMS). It is quite necessary to look at the ended distance education programs in Uganda since they laid ground for he modern distance education thriving in the country currently.

Corresponding Author: Bbuye Juliana, Department of Distance Education, Makerere University ,7062 Kampala, Uganda 
Ended donor funded distance education programs: The Mubende integrated teacher education which runs in the 990s was funded by action aid, a U.K. nongovernmental organization and the British overseas development scheme. The Uganda Government and the District Administration of Kiboga, the area where it was based contributed only $7.4 \%$. This was a project which was managed by a project coordinator through four student services centers. Study materials were developed by staff in the teacher training colleges and some other trained teachers outside the training colleges. It was observed that the materials proved to be for long term benefit. One of the objectives of that project was to assess the worth of distance education odel for replication throughout Uganda This objective was indeed fulfilled, (MITE evaluation report 1995) the splinter distance education programmes that replicated the MITEP programme were the Rakai integrated teacher education programme (RITEP) the Luwero Integrated Teacher Education program (LUTEP) and he Northern Uganda integrated teacher education programme (NITEP), some of its other achievements apart from quality learning materials were the opening of access to local untrained teachers to training in Mubende and Kiboga districts, use of local tutors to teach a larger number than would have been the case, credible examination processes nd a strong support service system through face to face sessions and support centers.

Northern Uganda integrated teacher education project: This project run between 1993 to 1998 and was funded by e World Bank. It was run by The International Extension College of UK. It was part of a wider project, the northern Uganda reconstruction program NURP in an effort to restore and reconstruct devastated northern areas as a result of 10 year civil strife. It trained 3000 untrained teachers in northern and North eastern Uganda ${ }^{[6]}$. Adopted MITEP materials which had been developed so far basing on courses for primary teachers. To ensure quality, students on the course sat similar examinations of the country Grade 111 teachers syllabus(primary or elementary teachers level) This has been so far the most successful program, partly because of extensive resources which allowed for even a personal tutor scheme. Wrightson 1998 says $64 \%$ of the teachers trained passed and increased teachers in northern $\mathrm{n}$ Uganda by $53 \%$. The program registered only $11 \%$ dropouts. Lessons drawn form such a successful project are; that distance education requires high investment in fixed costs, ell written study materials, and a strong support system. NITEP however did not live longer than the donor period, an indication of the difficulties the developing nations go through to sustain systems whose funding originates from donors. The high costs could not be maintained by the local district administration and the central government.
Teacher development and management systems (TDMS): In service distance education program through teacher development and Management systems (TDMS), is another donor funded program which run between 1997 to 2000 . It is again for primary teachers. It was also funded by USAID and covered the whole country. The project link Primary Teachers Colleges to a network of primary schools and provides field based upgrading and continuous service training for school managers, instructional staff, inspectorate staff and teachers Odaet ${ }^{[7]}(1997$, this is one of the distance donor funded program which has been sustained after donors leave. It has been incorporated into Kyambogo University and offers training to teachers using distance flexible education that suits the needs and conditions of the learner. The teachers carry out their normal work in the school and at the same time study. It has a very strong support system where teachers on training teach and are supervised by the head teachers on any other competent teacher in the school who acts as a personal tutor. This has proved to be a very successful model, which ensures that support so crucial to a distance learner is available. Quality of teaching in primary schools has improved through that distance education teacher training project, it is also an integrated program which has led to the construction of classroom blocks, provision of computers and massive reproduction of study materials. It has brought more equity in the provision of trained teachers in the various parts of the country since each region has a Primary core Teacher Training College. Enrollment figures have also increased for teacher training, attrition rates at primary levels have also reduced as a result of more trained teachers teaching, more physical facilities having been provided and access for marginalized groups as girls having been improved.

Distance education at higher levels of learning (tertiary levels): Makerere University, offers one of the strong external degree program in Uganda. The External Programs also started with the help of donor funds. The Commonwealth of Learning provided funds for study materials and training of staff to run distance education. They also trained in the techniques of developing distance education study materials. A capacity for distance educators was therefore built, and that capacity at Makerere University has been used to extend programs in other higher institutions of learning in Uganda.

The external degree program of Makerere University consists of three degree programs Bachelor of Education (B. Ed) Bachelor of Commerce B.Com) and Bachelor of Science. The total enrollment is 7,000 students $(15 \%)$ of the total university enrollment. A total of 3000 students have graduated through the system. $10 \%$ of the graduands enroll on Masters program. 
One of the biggest achievements of the external degrees at Makerere University is the expansion of access to university education to those who would have previously missed the chance. For example the external program intake in the year 2005/06 in Bachelor of Commerce is 1,500 students compared to the internal intake of 400 students. Similarly, the Bachelor of education enrolled 900 students compared to 450 in the internal programs. The qualifying students for University entry grows every year and out of the 30,000 who qualified for entry only 20,000 have been admitted leaving out about 13,000 students. Of these the external degree admitted only 2,470 showing the need to improve distance learning programs and offer more access to intending candidates who wish to enter university. One of the major concerns of the Makerere External Program is the lack of support Centers up country. The former extra mural centers were expected to become key centers in the running of external degree programs. However those centers were dilapidated earlier on during the military regime of the 1970s and continued civil wars in the 1980s. The external degree program of Makerere University therefore has very weak support centers.

In 2000, Rockefeller supported one center in Mbale in the eastern region and the area is now networked, but this is still a drop in the water. Carnegie is also planning to support three other centers, which have not yet taken off because of logistics, since the University infrastructure is still lacking. The major support for the external program of Makerere University ideally should be in the area of support centers, equipment to embrace the modern delivery system of distance education using ICT. Another concern for the programs is the lack of locally developed study materials. The Carnegie program has done a good job through the development of science study materials with over 60 books being in press. This has been possible because of the heavy funding poured in through the donor support, but where there is no support like in the area of Education and B. com, the program is suffering as far as study materials are concerned. The student fees alone which are kept low for equity reasons cannot support development of study materials. Over 40 titles are awaiting print, but there are no funds. This leads to the heavy dependence on face to face sessions and study groups which sometimes study daily with the help of some tutors, which is not a good development for distance education. There is therefore inevitably heavy dependence on face to face sessions. The success story of $1999 / 2000$ where the intake was 3,250 a $33 \%$ increase over the previous years is slowly ending with intake figures falling bellow a $20 \%$ increase in the precedent years up to 2005. This is partly because of the lack of decentralized programs upcountry and lack of strong support for the students on the course which are indeed so imminent in the priorities of distance education. There is however a ray of hope.
The Rockefeller funds would assist in the development of ICT based centers although the bureaucracy of the university is preventing some of programs from being approved. However it is the wish of the managers of this program that more funding is poured in the program to develop an herb for the Open University of Uganda.

Kyambogo University distance learning programs: Kyambogo university is the second largest University in the country, which was merged out of three institutions, Kyambogo Polytecnique, and Uganda National Institute for Special Education in the year 2001. two distance education programs, the Diploma in Primary Education and Grade 111 teacher program. It acquired the TDMS network of coordinating teacher training colleges in all the regions of Ugand,and its programs are therefore modeled under the NITEP and TDMS earlier program with strong outreach centers up country unlike Makerere University External Programs. They have embarked heavily on the development of study materials and boast of enrollment of about 4000 students spread up country. It is a highly decentralized and self sustaining program with outreach centers in most of the teacher training colleges which number about 20.The distance education programs are growing rapidly and the department of distance education has been elevated to an institute at Kyambogo University. This is because of the great sensitization of the top administration which went through a strong orientation with the Leeds University Staff of UK, a partner in the development of distance education at Kyambogo University. The African virtual university A highly potential distance learning program which has suffered as a result of withdraws of donor money. It was meant to increase the number of scientifically and technically innovative and also a highly adoptive, receptive and a problem solving people with a predisposition for life learning. The pilot phase run from e 1997 to 1998 and it was supposed to become self-sustaining. However the need for heavy investment has hampered that dream. The country cannot afford that heavy investment. Uganda is a poor country, the mobilization of adequate needed resources is difficult, basic telecommunications infrastructure is not yet in place for the whole country to be served effectively though education technology. The charges for phones and broadcast are to high to be used by education institutions, there is irregular power supply which affects operations. The Virtual University presently if town based with only the affluent using it. One of its greatest achievement however is that it sparkled off the start of the Bachelor of Science External in Makerere University, when the professors who participated in the coordination of courses during the pilot course realized that it is possible to offer science using the distance education mode. 
The global learning center: This is also another heavily donor funded project which offers satellite based learning up to PHD level. The major problem with the center is indeed sustainability. However, it promotes quality education and plays a role in disseminating a wide range of information. If the initial capital to install the required basic infrastructure can be obtained, the costs would be lower than the conventional means of training scientist in Uganda a country so deprived of them. There is also need to eliminate cultural bias, the transmitted lectures preferably should be developed by indigenous lecturers. At the moment most of the lectures are transmitted from the USA, Canada and British Universities which though very good is affected by the ability of the students to understand the accent and also by the disparity in in curriculum implementation. This is because, whereas in Uganda, the students enter University after studying for about 14 years they sit for level examinations, in America, students enter University after 12 years of study. Some times the students in Uganda, find some of the courses repeating what they have already covered and give up. However the center provides one of the most Extensive Internet providers in the country. Uganda Mattrys University distance education Programs Based in Central Uganda, the University offer diploma courses on educational Management and Microfinance for Bankers and is planning to set up degree courses of Bachelor of Education. with over 4500 students on the program, the external students are more than the internal students who number 1,500 only. This shows the growing need of Ugandans to study using the flexible distance education mode. The success of the University is based on the revolutionary move taken by the implementers of theis program to use all catholic parishes in the country with educational secretaries as study centres. The centres recruit and support the students and it is a highly decentralized program with over 30 study centres.

Non formal distance education programs: One of the major non-formal (non-credit) programs in Uganda is the Ministry of Health Continuing distance Education Programs. The objective of the program is to improve the status of Uganda people through the provision of high quality health services. The target group for the course is middle level and operational level health workers. The program has been in existence since 1986 and has two components, correspondence courses and radio program entitled facts about Health The correspondence courses have proved to be ideal for motivated health workers. They are cheap and cost effective compared to the conventional programs of continuing education and can be availed to many health workers, including those in remote areas. The program is run through satellite centers based at Fort Portal, Kasese.
Kapchorwa, Masindi Kibale, Masaka and Gulu Programs: Since there is little or no disruption of work for health workers, who are limited in number, the courses are a great asset to the Ministry of Health and to the community at large. Midwives, nursing aides, enrolled midwives have improved their skills. Enrollment since inception is 5,500 which are quite extensive. The program however is very popular among health workers who desire to acquire more knowledge and skills particularly in the medical field which is dynamic and always changing. There is evidence that health workers who have enrolled on the course have improved their skills in prescription of medicine, control of diarrhea, malaria and sexually transmitted diseases, and also clinical assessment of both children and adults. The health distance education program, however, is fully sponsored by donors with participants paying money only for hostage. This is very unhealthy condition that can lead to sustainability of the program. Plans to institutionalize it, unlike the TDMS are not in place yet. It should indeed be unfortunate to loose such a program in a field that so greatly needs training as the health field. The program has some problems typical of most distance education programs in the Developing World. Communication between learners and centers is still poor due to the poor infrastructure. Indeed many posted letters and posted materials are lost on the way. Similarly, record keeping is still lacking efficiency and face to face sessions are kept to a minimum because of limited resources despite their tremendous value through giving learners chance to meet with each other, meet tutors, and share experience to solve problems. Due to limited qualified manpower, supervision of learners is irregular, and completion rates, are very low: 11\% (1998). Similarly, as in the External Degree Program of Makerere University, discussed above, the health, manpower program is faced with very high demand for the course and yet staffing is still poor. Besides, remuneration is not attractive enough and this has effect on quick making of scripts.

Radio programs of the ministry of health distance education programs: The Radio programs associated with the Health non-formal Distance Education, on the other hand, have not been very effective. The programs are put on air on an unattractive alternative channel at an inconvenient time $(9.30 \mathrm{pm})$ and are not therefore attractive against other competitive programs. A recent evaluation showed that only $5.7 \%$ of health workers listen to it regularly. It could be a culture in Uganda that radio is not yet regarded seriously as a media of teaching and learning. Most educational programs on radio and TV are hardly listened to or observed by the relevant audience.

Community based child care open learning program: Another non formal distance education program which has incidentally ceased operation is the 
community based childcare open planning program. It was launched in October 1997. The target was staff working in childrens homes and institutions. The aim was to increase the quality, standards and professionalism of those who worked with children. Hence courses on child health and nutrition, child growth and development. The specific aims of the program where

* To improve the quality of children care and protection in the community.

* To provide mother and child care in the communities.

* To promote the support of sick children

Prevention of some diseases that affect children Develop community based health care units in the communities. Enable communities to apply knowledge of stages of development to help children grow well. Teach the necessary social habit to children according to their culture and let them use the habits properly. Develop community initiatives for management / prevention of problems of children in difficult situations and their root causes. Explain situations, policies, laws and practices affecting children in Uganda. Promote the use of resources available to the community. Improve and sustain children welfare development in community; and Promote collaboration between the community and appropriate welfare organization. The decision to use distance education in this non-formal community program was based on the growing need for training among child care workers which could not be met by traditional conventional forms of education, and the community, who formed the biggest numbers of participants of working adults in communities and needed to be in their situations most of the time. May of them like primary teachers had been deprived of education because of fees, family interference and other personal problems. May of them, though educated required an improvement in skills and knowledge of community and to update their knowledge and skills. Those who participated gained a lot since it was based at the ministry of gender and community development. The program may be rejuvenated. The study materials had already been put in place. The span for the program was too shot. It was not evaluated and its difficult to access the impact. However, judging from objectives, course content, and the evaluation carried out, the program as worthwhile.

Schools distance and open learning programs in Uganda: World Link And School Net World link and school net are the other distance education programs that have developed in Uganda. The programs aim at linking schools in Uganda to schools in Canada through the Internet and also to link schools within Uganda. A number of programs have been developed and it may be possible to download a variety of materials from a variety of subjects to reach schools which would other wise not be obtained, thus increasing quality of secondary schools in Uganda. Lack of developed telecommunication systems in one of the problems faced by the world link programs in Uganda. Indeed it is evident that lack of electrification in the rural areas will make information communication technology integration in distance education a possibility for the heavily resourced (donor Funded) programs mainly.

Indicators of modern distance education delivery methods in the Uganda distance education programs: As far as modern distance education delivery methods are concerned, Uganda can boast of very few as indicated below:

* Satellite delivery of lectures at the Global Learning Centre and the African Virtual University

* The internet linked study centre (only one) at Mbale of Makerere University

* The collaboration that allows students to use internet facilities at a variety of institutions in Uganda, but which are nonetheless very slow especially upcountry and discourage some students

* Use of blackboard chat in some of the internal programs which have adopted e- learning which has however not been extended to distance learning students yet

* Development of a few CD Rom materials for the B.Sc Program of Makerere University lectures becoming more internet alert and drawing the attention of students to internet sources and sometimes forcing them to submit assignment through e mail e.g students on the Bsc Computer Science option

* Making ICT basic course compulsory for all students who go through Makerere University and for staff seeking for promotion.

* School network program making students aware of internet facilities long before they enter University. The challenges of modern distance education delivery methods in the Uganda Distance Education Programs

* Lack of resources both financial and human to implement the modern techniques

* Iniquity in allocation of resources in dual universities

* The underdeveloped nature of the country with regard to telephone linkage and power supply which are based mostly in the Capital City but very unreliable in the upcountry towns

* The very few computers available for use in the institutions and learning centre because of the prohibitive costs which make it difficult for even post graduate students to own one

* The dominantly conservative administrators and some tutors who require sensitization to bring them on board the ICT train. 
* The majority of students who enter university and teacher training colleges where distance education is used are not computer literate.

\section{CONCLUSION AND WAY FORWARD}

The conclusion is that, considering the status of Uganda in world economics development of distance education in the country has been modest. In the beginning it was growing steadly but was interrupted by civil strife. However, in the late 1980s Uganda steady economic growth led to a steady development in the field of distance education. What is evident though is that, the private sector has not yet invested in distance education heavily, as was the case in the industrialized countries. Donor funding however has assisted in the development through the MITEP, RITEP, NITEP and TDMS.programs and this has contributed heavily to the increase of trained teachers and development of capacity for Uganda's institutions to offer distance education especially the training offered through commonwealth f learning and USAID. In Makerere University, distance education has raised substantial funds for the institution in response to the privatization schemes. The External Degree Program of Makerere University has led the way in the development of selfsustaining distance education programmes. It offered a lesson to the Kyambogo University, Diploma of Distance Education in service teacher programs, and the Diploma in Education Management as well as Diploma in Education at Uganda Mattrrys University Nkozi, who capitalizing on challenges observed at Makerere University are fully decentralizing their program and the management are giving full support to the programs though in a dual mode university. All those new programs are self sustaining there is need therefore to strengthen the Makerere University program, which incidentally has more students and has capacity to expand programs for distance learning.

Non formal Distance Education Programs have not been fully developed but persistent delivery of the Health Manpower Development Distance Education Program is likely to set the precedent for other nonformal Distance education programs to develop. Uganda however is yet to develop a nucleolus for the development of distance education. All the programs mentioned above are fragmented pieces of innovation which need to be backed strongly by implementing a policy so well intended, and stated first in the 1960s and repeated vehemently in 1991 in the white paper of education that an open university in Uganda be established. This however cannot be followed unless government takes a bold step and sets up a governing committee to steer the development of an open university in Uganda.
That set aside, it is also high time, noting the delay in the establishment of an open University, and the logistics thereof required, that the distance education units in dual universities in Uganda are assisted to consistently develop distance education programs by making those units strong financially and arranging for more establishments to enable them run support centres. If all that is implemented, supported with the development of a strong technologically based learner support system, distance education would boom in the country. None the less we cannot run away from donor support. This support is vehemently needed in the development of modern distance education implementation techniques which are greatly supplementing the use of print as the major delivery method in distance education . distance education in Uganda also ought to become a multimedia program. Suggested support programs training of staff to develop materials using modern distance education techniques Strengthening study centres through making them complete ICT centres with enough computers, facilitators, television and radio sets, printers scanning machines and photocopiers Sensitization study visits of key senior implementers of policy in key positions in Ministry of Education and Universities and Continued north to south cooperation and networking in the development of modern distance education,delivery methods.

\section{REFERENCES}

1. Aguti, J.N., 2000. Distance Education in Uganda. Paper delivered at the Workshop on the support for Distance Education Students at Hotel Africana Kampala Uganda.

2. Nsamba. S. and D. Atim, 2004. Fifty years of adult education at Makerere University. Institute of Adult and Continuing Education, Makerere University.

3. Bbuye, J., 1999. Distance education in Uganda, development, practices and Issues. Uganda $\mathrm{J}$. Education.

4. Kironde Report, 1966. Report of the visitation committee to Makerere University. Ministry of Education, Uganda.

5. Muwanga, M., 1987. Evaluation of educational Radio of the Ministry of Education in Uganda. Ministry of Education, Uganda.

6. Ordukene, J., 1995. Distance education in Uganda. Unpublished.

7. Odaet, C.F. and F.M.N. Higwira, 1994. Design of outreach tutor training plan for residential induction and training of outreach tutors: A Report to Super Ministry of Education and Sports. (Unpublished). 